\title{
Role of the mixing conditions and composition of galvanic sludges on the inertization process in clay-based ceramics
}

\author{
J.M. Magalhães ${ }^{\text {a }}$, J.E. Silva ${ }^{\text {a }}$, F.P. Castro ${ }^{\text {a }}$, J.A. Labrincha ${ }^{\text {b,* }}$ \\ a Department of Mechanical Engineering, University of Minho, 4800 Guimarães, Portugal \\ ${ }^{\mathrm{b}}$ Ceramics and Glass Engineering Department, CICECO, University of Aveiro, 3810-193 Aveiro, Portugal
}

Received 22 September 2003; received in revised form 11 November 2003; accepted 11 November 2003

\begin{abstract}
Hydroxide-metal sludges from electroplating industry are a potential source of environmental contamination due to their high content of heavy metals. The incorporation of these residues in a ceramic matrix can be a promising way to suppress the harmful effect of metals normally present in those sludges. This work reports the role of the mixing time between the waste and ceramic materials and of the calcination step on the fixing level of several metal-containing species ( $\mathrm{Al}, \mathrm{Zn}, \mathrm{Ni}, \mathrm{Fe}, \mathrm{Ca}, \mathrm{Cu}, \mathrm{Cr}$ ) after sequential leaching in different media (aqueous, acetate and citrate). A strong and/or long mixing process will promote the deagglomeration of the coarser agglomerates and then will increase the reactivity of remaining grains towards the ceramic material during the calcination. As a consequence, inertization is improved for fired samples. With non-calcined samples leaching increases as a result of increasing dispersability/availability of species.
\end{abstract}

(C) 2003 Elsevier B.V. All rights reserved.

Keywords: Galvanic sludges; Metals; Inertization; Ceramic matrix

\section{Introduction}

Leaching characteristics of chemical substances and their relation with environmental aspects and pollution is a relevant research topic in recent years. From this study, many chemical products have been classified according to its potential danger to health and environment. Sludges produced by the physico-chemical treatment of wastewaters generated by electroplating plants are potentially eco-toxic residues [1]. This is because of the high mobility of metals, such as chromium, nickel, copper and zinc, present in these wastes. Methods for the treatment of these residues could employ physico-chemical means, like hydrometallurgical routes. However, the high compositional heterogeneity of the sludges from one treatment plant to another, makes it impossible to envisage an overall treatment for these residues. Pure substances show, normally, a potential higher leachibility than diluted or dissolved ones. This might be explained by the fact that pure substances present unitary chemical activity, whereas diluted or dissolved substances

\footnotetext{
* Corresponding author. Tel.: +351-2343-70250; fax: +351-2344-25300.

E-mail address: jal@cv.ua.pt (J.A. Labrincha).
}

have chemical activity lower than one. This principle is the theoretical key of processes of stabilisation and inertization of sludges and solid residues by inclusion in a ceramic matrix [2-7]. In fact, clay-based ceramic products are potentially good incorporation agents of residues, due to their typical mineralogical compositions, involving silicate phases that can dissolve considerable amounts of metals in the structure [8,9], and also because the high firing temperature conditions normally used. Some more advanced and scientific approaches attempt to produce technical ceramics (refractories, electrical insulators, etc.) by using waste as the main component [10-14].

Chemical fixation of species might involve macro or micro-encapsulation mechanisms, according to the nature of components involved and the operational conditions (e.g., firing schedule) $[15,16]$. The effectiveness of this inertization technique is then dependent on several experimental parameters, as described in another paper [17]. Amongst all, the effects of mixing/homogenisation time during the preparation of mixtures and the nature of the sludge were found relevant and are detailed in the present paper. Several galvanic sludges are added to a typical brick-making clay-based matrix and the fixation level of metallic species was determined by sequential leaching in several media. 
The description of several trials of ceramization of different wastes is now common, but no details about the fixation mechanism and the relevance of experimental variables are given. This work partially attempts to go further in these aspects.

\section{Experimental}

As inertization matrix, a typical brick-making formulation involving the mixture of two red clays was used, showing the following average chemical composition (wt.\% in a dry basis, estimated by XRF-X Unique II Philips): $\mathrm{MgO}$ (1.54\%), $\mathrm{Al}_{2} \mathrm{O}_{3}(28.0 \%), \mathrm{SiO}_{2}$ (46.1\%), $\mathrm{K}_{2} \mathrm{O}$ (3.86\%), $\mathrm{TiO}_{2}$ $(0.67 \%)$, and $\mathrm{Fe}_{2} \mathrm{O}_{3}(17.6 \%)$. Four sludges produced by the physico-chemical treatment of wastewaters generated by different electroplating plants were used. Chromium, nickel and copper electroplating are the main involved processes. Moisture content was determined in a special balance (Adam Co.-model AMB 310). Particle size distribution of dried and previously aqueous dispersed samples was obtained by a laser technique (Beckman Coulter LS 230). The specific surface area (SSA) of dried samples was determined by the BET method (Gemini II 2370). Thermal behaviour of sludges was evaluated by differential thermal analysis (Rigaku Thermoflex) at a heating rate of $10^{\circ} \mathrm{C} / \mathrm{min}$. The chemical composition of dried samples was also determined by XRF. Each sample (about $1 \mathrm{~g}$ ) was then submitted to acid digestion and the quantitative analysis ( $\mathrm{Al}, \mathrm{Ca}, \mathrm{Cu}, \mathrm{Cr}, \mathrm{Fe}, \mathrm{Ni}$ and $\mathrm{Zn}$ ) of the corresponding eluate was obtained by atomic absorption spectrometry (AAS-GBC 904 AA). Mineralogical composition of previously calcined (at $1000^{\circ} \mathrm{C}$ ) samples was determined by X-ray diffraction analysis (Rigaku Denk Co.).

The sludges are amorphous and basically constituted by a gel of hydroxides (and sulphates). The average size of agglomerates is small, the moisture level is always over

Table 1

Chemical composition (AAS) of dried sludges, respecting the metallic species

\begin{tabular}{lllllllll}
\hline Sludge & wt.\% & & & & & & & \\
\cline { 2 - 9 } & $\mathrm{Al}$ & $\mathrm{Ca}$ & $\mathrm{Cu}$ & $\mathrm{Cr}$ & $\mathrm{Fe}$ & $\mathrm{Ni}$ & $\mathrm{Zn}$ & Total \\
\hline$A$ & 15.7 & 4.00 & 1.03 & 2.20 & 0.37 & 7.12 & 1.36 & 31.78 \\
$J$ & 0.26 & 0.36 & 1.50 & 2.42 & 2.31 & 48.7 & 1.02 & 56.57 \\
$M$ & 0.29 & 6.56 & 1.60 & 9.14 & 4.34 & 3.86 & 0.96 & 26.75 \\
$Q$ & 0.92 & 0.02 & 42.5 & 0.78 & 0.14 & 1.49 & 3.52 & 49.11 \\
\hline
\end{tabular}

Table 2

Leaching characteristics (DIN 38414-S4) of dried sludges (in mg/l)

\begin{tabular}{lllllllllll}
\hline Sludge & $\mathrm{Al}$ & $\mathrm{Ca}$ & $\mathrm{Cu}$ & $\mathrm{Cr}$ & $\mathrm{Fe}$ & $\mathrm{Ni}$ & $\mathrm{Zn}$ & $\mathrm{SO}_{4}{ }^{2-}$ & $\mathrm{Cl}^{-}$ & $\mathrm{pH}$ \\
\hline$A$ & - & 21.7 & - & - & - & - & - & 22.7 & 4.40 & 7.77 \\
$J$ & - & 1.20 & - & - & - & 49.2 & - & 94.2 & - & 7.38 \\
$M$ & - & 5.14 & - & 0.33 & - & - & - & 6.90 & - & 8.80 \\
$Q$ & - & - & 1.34 & - & - & - & - & 15.8 & - & 7.40 \\
\hline
\end{tabular}

The sign "-" corresponds to levels under the detection limit.

$50 \mathrm{wt} . \%$ and the dehydration process is very difficult to process in open air conditions. Table 1 gives the average chemical composition of the sludges, concerning the relevant metallic species. The sludge $J$ is basically constituted by nickel, while sludges $Q$ and $M$ are copper and (chromium + calcium)-rich, respectively. Sludge $A$ is more complex and contains significant concentrations of calcium, nickel, and chromium (see Table 1). Table 2 shows the composition of eluates from the leaching process in normalised conditions (DIN 38414-S4). Potential toxicity is related with metals extraction, in particular chromium and nickel. Sludge $J$ seems to be the most problematic, but the presence of chlorides in sludge $A$ might also impose experimental restrictions upon firing.

The mixture between the sludge and clay-based materials ( $1: 1 \mathrm{wt} . \%$ ratio) was conducted in wet conditions, as an attempt to optimise the process. An amount of $150 \mathrm{~g}$ of each component (previously dried and sieved at $125 \mu \mathrm{m}$ ) and distilled water was added to reach a total weight of $600 \mathrm{~g}$. The mixtures were slowly agitated during $72 \mathrm{~h}$ and then dried at $110^{\circ} \mathrm{C}$ over one night. A sequential leaching procedure was conducted on dried (named reference mix) and previously fired (at $1000^{\circ} \mathrm{C}$, during $30 \mathrm{~h}$ ) mixtures by using the consecutive solutions: (i) distilled water; (ii) sodium acetate/acetic acid at $0.5 \mathrm{M}(\mathrm{pH} \approx 4.70)$; and (iii) potassium citrate/citric acid at $0.5 \mathrm{M}(\mathrm{pH} \approx 3.1)$. Leaching was performed by using $40 \mathrm{~g}$ of solids and $400 \mathrm{ml}$ solution, during $24 \mathrm{~h}$ under permanent (slow) stirring. Twenty milliliters leached samples were collected after regular periods and the total amount of solution was kept constant by adding $20 \mathrm{ml}$ of fresh solution. A total of seven samples were collected for each leaching solution and the final concentration of relevant metallic species was determined by AAS. Maximum uncertainty of determinations was estimated as $5 \%$.

The effect of mixing time was evaluated with sludge $A$ by collecting samples after $24 \mathrm{~h}(A I)$ and after the normal time of $72 \mathrm{~h}(A 2)$.

Table 3

Relevant physical characteristics of sludges

\begin{tabular}{llllll}
\hline Sludge & $\begin{array}{l}\text { True powder } \\
\text { density }\left(\mathrm{g} / \mathrm{cm}^{3}\right)\end{array}$ & $\begin{array}{l}\text { Moisture } \\
\text { content }(\%)\end{array}$ & $\begin{array}{l}\text { Mean particle } \\
\text { size }(\mu \mathrm{m})\end{array}$ & $\begin{array}{l}\text { BET specific surface area } \\
\text { of dried sludge }\left(\mathrm{m}^{2} / \mathrm{g}\right)\end{array}$ & $\begin{array}{l}\text { BET specific surface area of } \\
\text { calcined }\left(1000{ }^{\circ} \mathrm{C}\right) \mathrm{sludge}\left(\mathrm{m}^{2} / \mathrm{g}\right)\end{array}$ \\
\hline$A$ & 2.49 & 60.9 & 88.2 & 41.29 & 0.93 \\
$J$ & 2.68 & 80.0 & 110.4 & 12.43 & 3.67 \\
$M$ & 2.29 & 70.3 & 99.0 & 65.71 & 0.22 \\
$Q$ & 2.51 & 76.6 & 86.3 & 48.02 & 1.53 \\
\hline
\end{tabular}


(A)

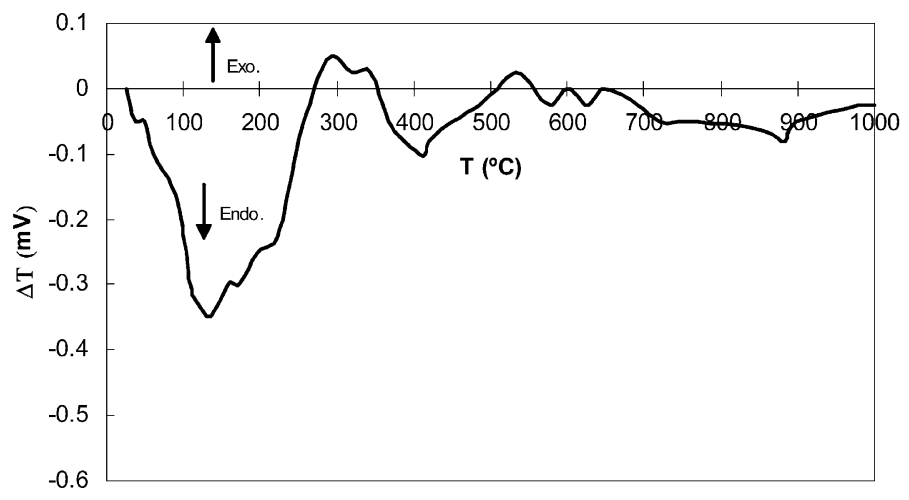

(B)

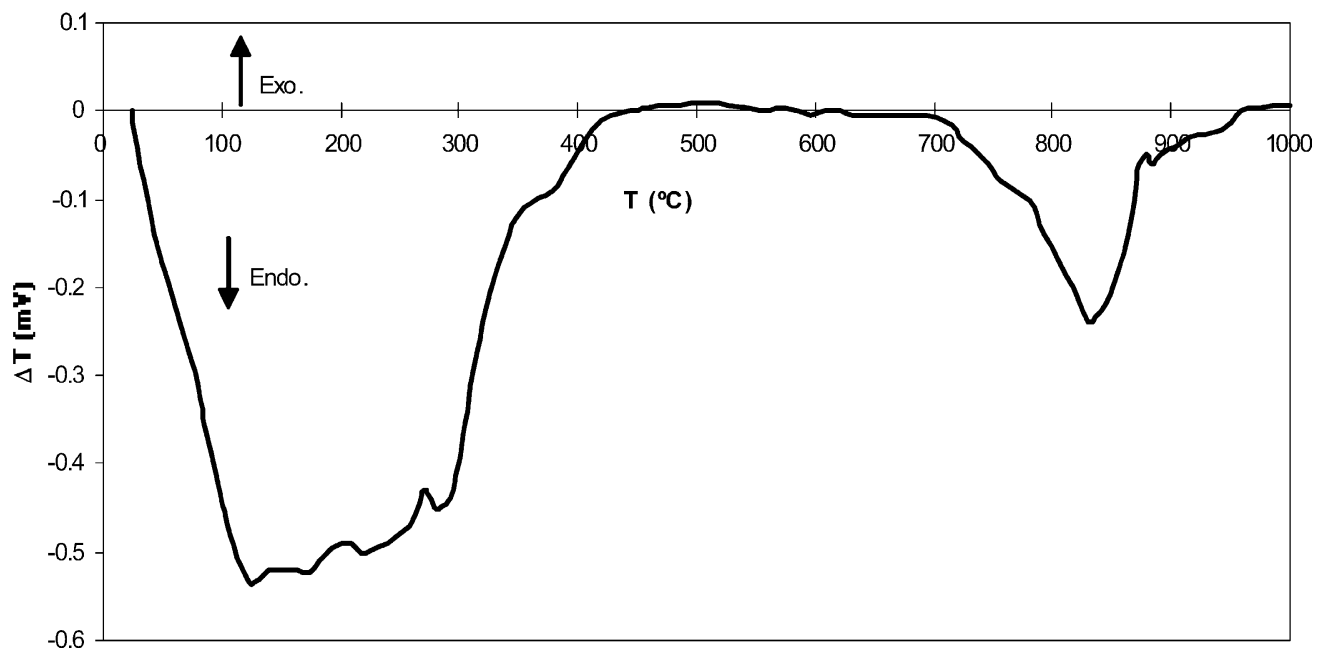

Fig. 1. Differential thermal analyses of the sludges: (A) $J$ and (B) $M$.

\section{Results}

\subsection{Characterisation of sludges}

Table 3 gives the relevant physical characteristics of the sludges. As expected, all residues have very high moisture levels (over $60 \mathrm{wt} . \%$ ). True density of powdered samples reflects the ratio between metallic and non-metallic $(\mathrm{OH}$, sulphates, etc.) components and tends to increase as this ratio enhances, as is easy to conclude from the analysis of Table 3. Samples $J$ and $M$ show maximum differences. DTA/TGA analyses (Fig. 1) confirm the presence of a higher amount of heat-decomposable species (OH, sulphates) in sludge $M$.

The relationship with particle size distribution (Table 3 and Fig. 2) is not obvious, since results were obtained with non-dispersed samples as typically used in current processing conditions. Partial deagglomeration might occur during slow mixing of suspensions but no severe changes in size distribution are predicted unless dispersing/deflocculating agents are added. In this case, differences are very small since the determined size corresponds to agglomerates and not to individual particles. All samples show maximum particle size of about $250-300 \mu \mathrm{m}$, confirming their fineness and the unneeded use of previous milling step before mixing with ceramic material. By contrast, values of specific surface area
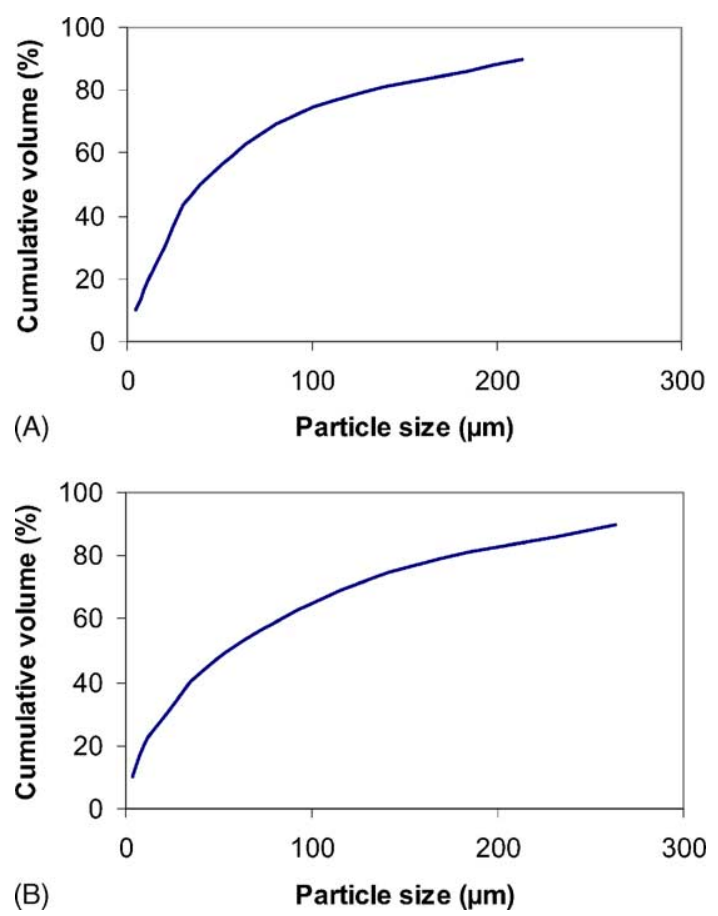

Fig. 2. Particle size distribution (cumulative curve) of sludges $A$ (A) and $M$ (B). 
of dried samples are related with the mentioned (ratio) composition. In fact, metallic-rich sludges are denser and corresponding SSA values tend to be lower (see sludge $J$ ). The same reasons might explain the high SSA value of $M$ sludge.

SSA values of calcined sludges reflect mostly the starting (dried) values, in the sense that dried samples having higher SSA values are more reactive and sinterable. Upon firing and after decomposition reaction had been completed, particles tend to agglomerate and coalesce and final SSA values tend to decrease when compared to those of samples less reactive. Comparison between samples $M$ and $J$ is again illustrative. Effects on leaching behaviour of calcined samples are then directly predicted.
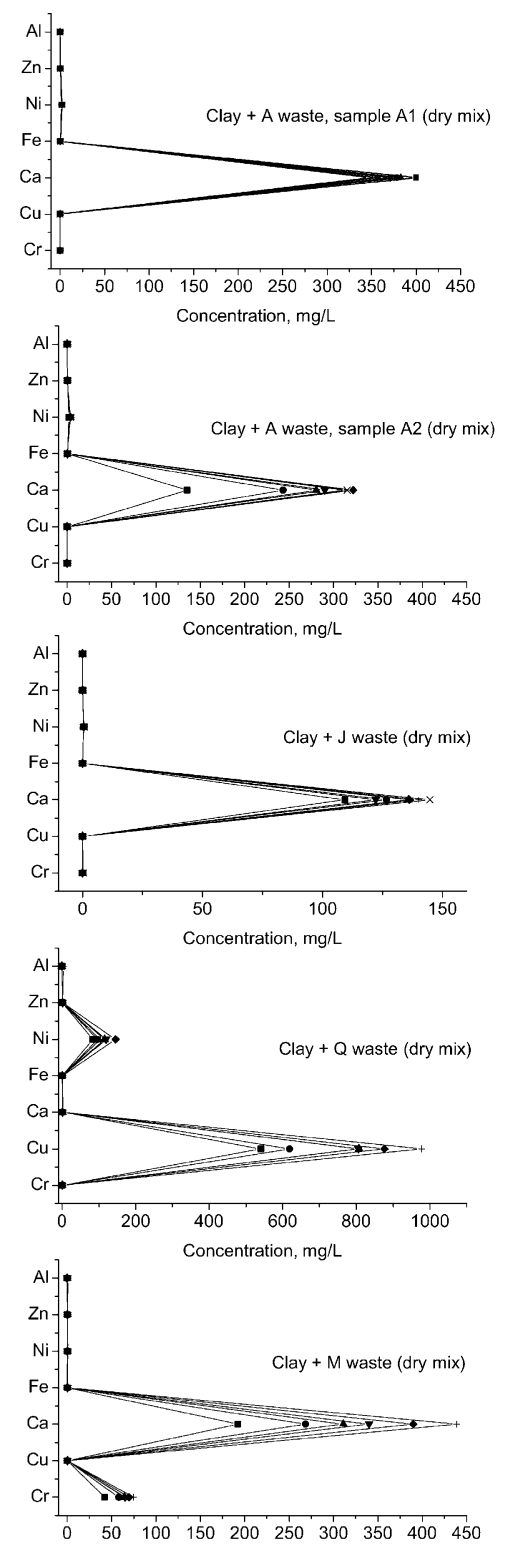
Concentration, $\mathrm{mg} / \mathrm{L}$

Leaching time in aqueous media $(\mathrm{min})$

$--10 \quad-\quad-80 \quad-\mathbf{- 1}-150 \quad \rightarrow-220 \quad \bullet-290 \quad-+-360 \quad-\times-430$

Fig. 3. Leaching behaviour of sludge/clay mixtures in aqueous media.

\subsection{Leaching behaviour}

According to the mentioned physical parameters we should expect higher leaching levels of non-metallic species from sludges that are richer in those components and show higher SSA values (e.g., $M$ ). By looking to Table 2, it results clear that this hypothesis is not observed. Extracted levels of $\mathrm{SO}_{4}{ }^{2-}$ are higher from sludge $J$ than from sludge $M$, pointing out the complexity of the leaching mechanism and possible changes on physical properties during tests.

Leaching results of reference mix samples (Figs. 3-5) clearly reflect the nature of each sludge, in the sense that highest removed species tends to be the corresponding
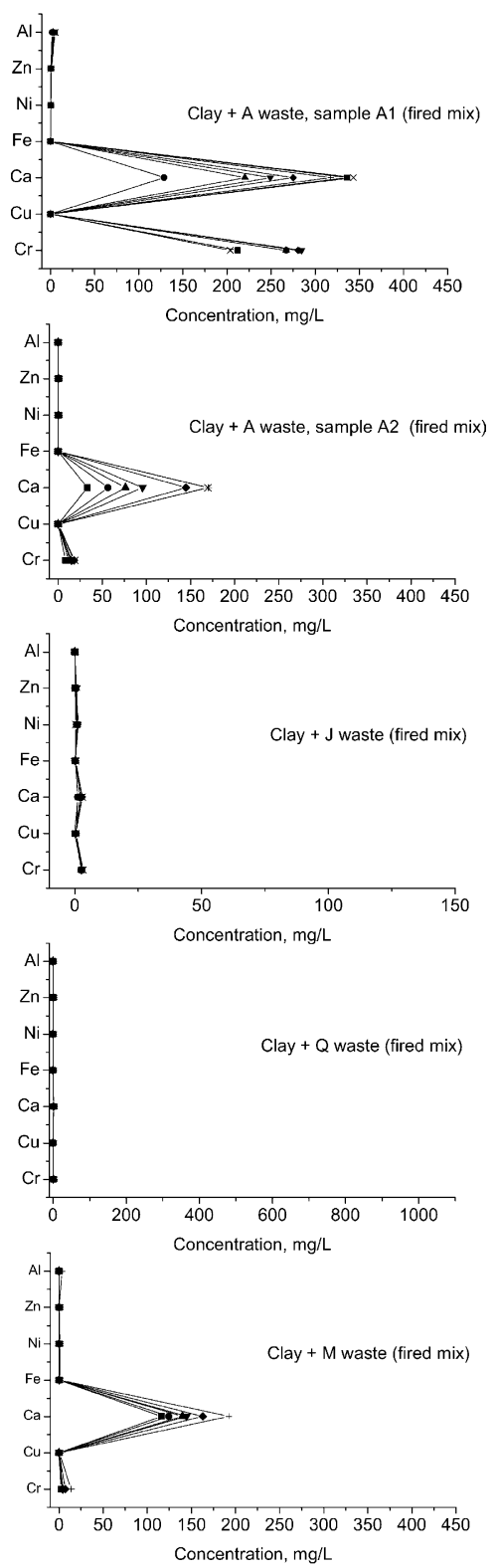
Concentration, $\mathrm{mg} / \mathrm{L}$

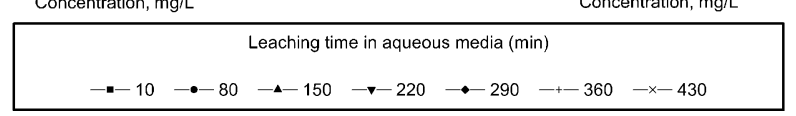



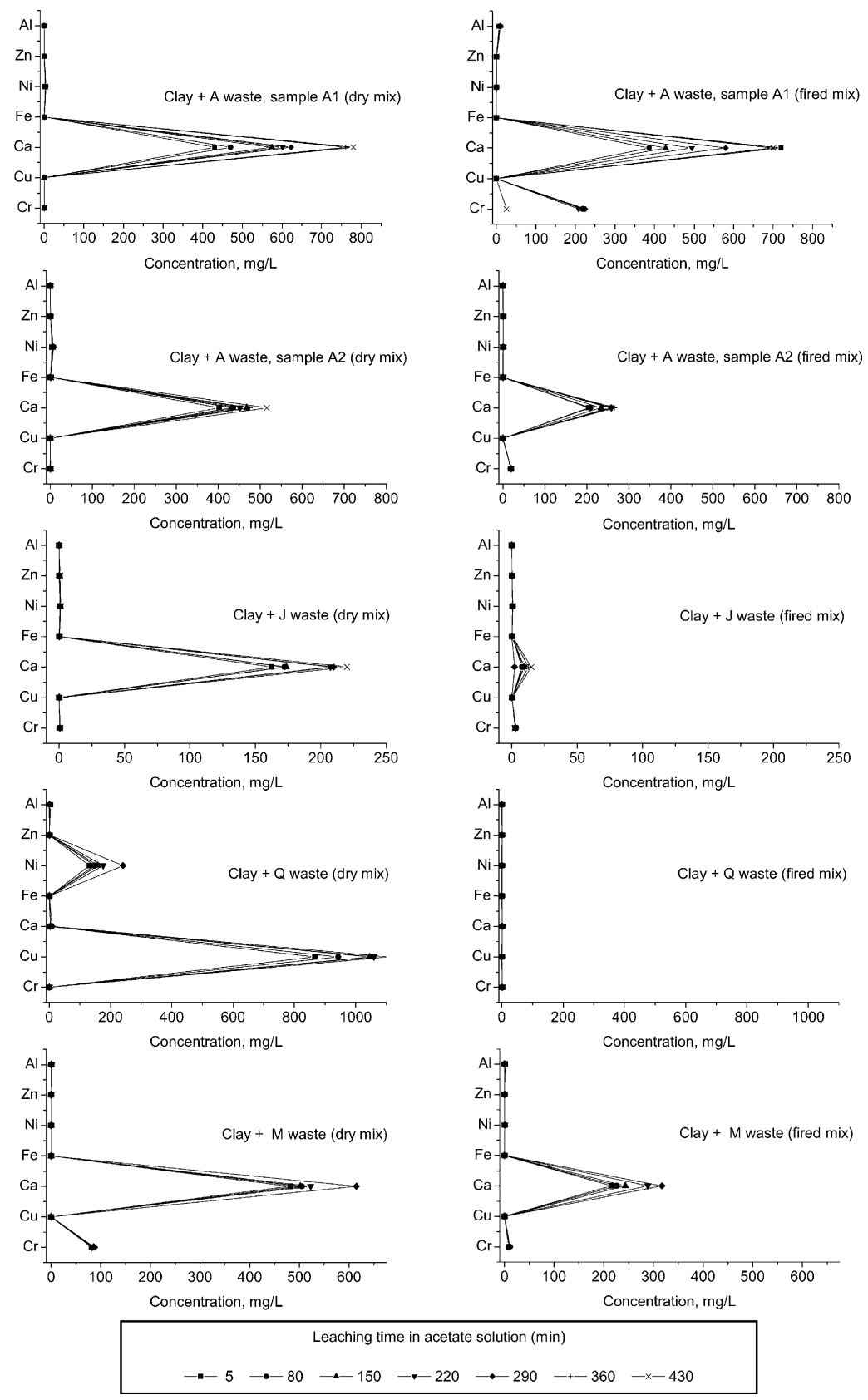

Fig. 4. Leaching behaviour of sludge/clay mixtures in acetate solution.

richest one (e.g., $\mathrm{Cu}$ from $Q$ sludge). However, intrinsic mobility of each metal and the type of extraction media strongly influence these results. For example, the extraction of aluminium is almost null in aqueous and acetate solution even from sludges where it is the dominant species (e.g., $A$ ). Removal is only detected in more aggressive conditions (low pH citrate solutions) but its level is still low. By contrast, calcium ions are strongly extracted in all conditions, even from samples where its concentration is relatively small (e.g., $J$ ). The only exception corresponds to sludge $Q$ in aqueous and acetate media, where its initial concentration is very small. This general tendency is also observed and emphasized with fired samples, as will be discussed later. As predicted, the use of higher aggressive leaching media (from aqueous to citrate solutions) tends to improve leaching levels for all species.

Inertization effectiveness was evaluated with sludge:clay fired mixtures. Figs. 3-5 also give extraction results from such samples. It seems possible to observe a tendency for a decreasing extraction level of metallic species from sludges that possess higher concentrations of metals (e.g., $J$ and $Q$ ), despite the obvious relevant differences on sludges composition. The behaviour of sludge $M$ seems to be in the opposite side. Despite the relatively low amount of metallic species, amongst those chromium is the dominant one, the extraction level of several species is appreciated even in aqueous 

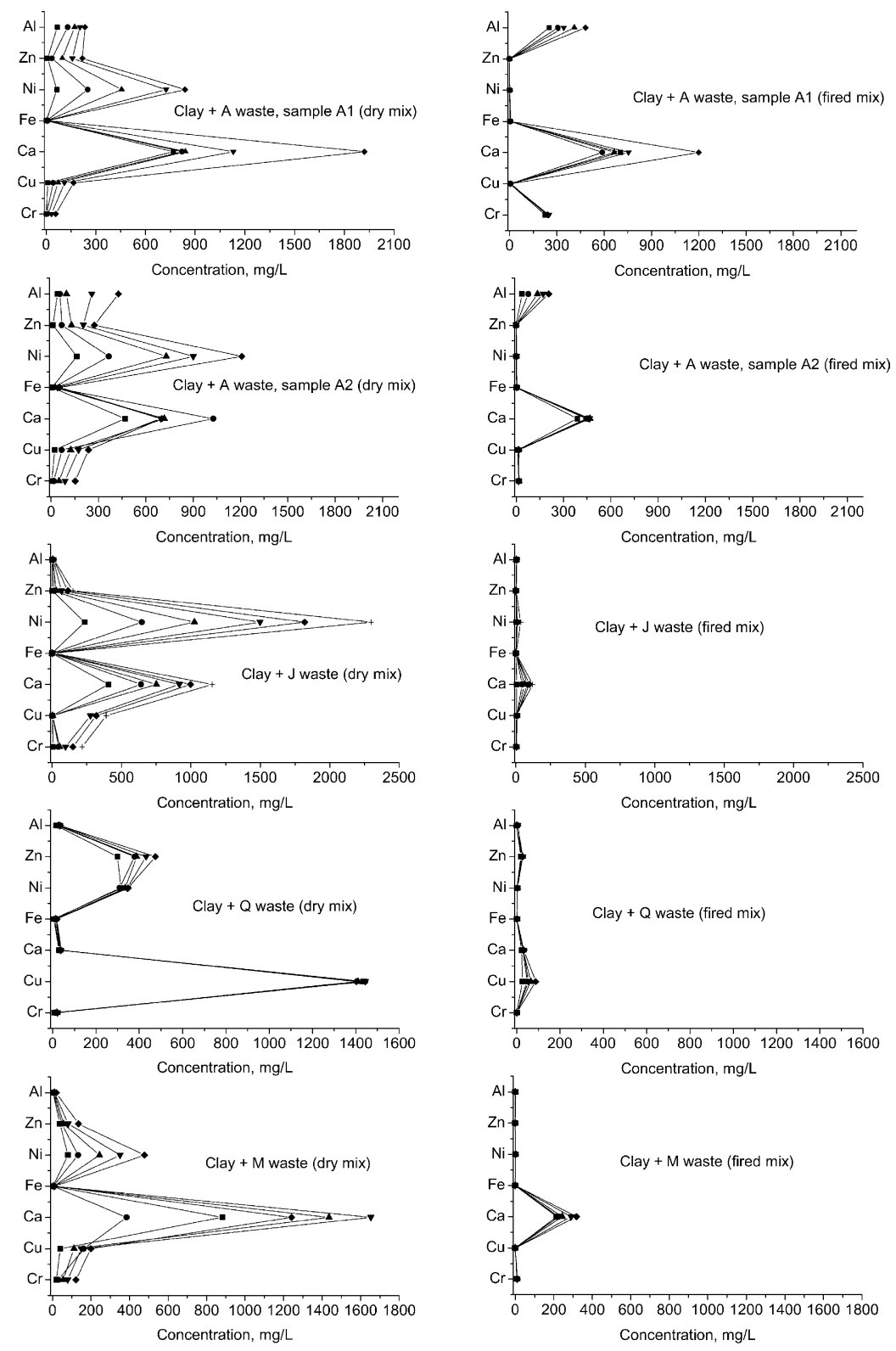
Concentration, mg/L

Leaching time in citrate solution $(\mathrm{min})$

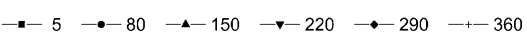

Fig. 5. Leaching behaviour of sludge/clay mixtures in citrate solution.

media. Calcium and chromium are the strongest removed species but through citrate leaching, $\mathrm{Ni}, \mathrm{Zn}$ and $\mathrm{Cu}$ are also leached. This apparent contradiction is certainly related with effects induced by physical parameters (e.g., SSA values) and the magnitude and nature of decomposition reactions during firing. Upon heating, decomposition of hydroxides is still significant but has lower magnitude in metals-richer than in the other sludges. Physical changes are also weaker in those samples, as denoted by lower relative changes of SSA values. Less severe changes in morphological/physical aspects might improve intimate contact towards the clay particles since earlier heating stages and then contribute to a more effective reaction between the two components. In other words, the physical disconnection between clay and sludge particles imposed by severe decomposition reactions of sludge (for example, in $M$ ) will retard chemical reactions between the two components, somewhat independently of their chemical composition. Moreover, metals-rich sludges are generally higher sinterable and act as a fluxing agent in the promotion of a highly closed-packed microstructure. Comparison of microstructures of fired samples made of pure sludge (Fig. 6A) and sludge:clay mixtures (Fig. 6B) confirms those differences. Sludge-pure samples show finer particles and higher amount of glassy phase, while clay ma- 


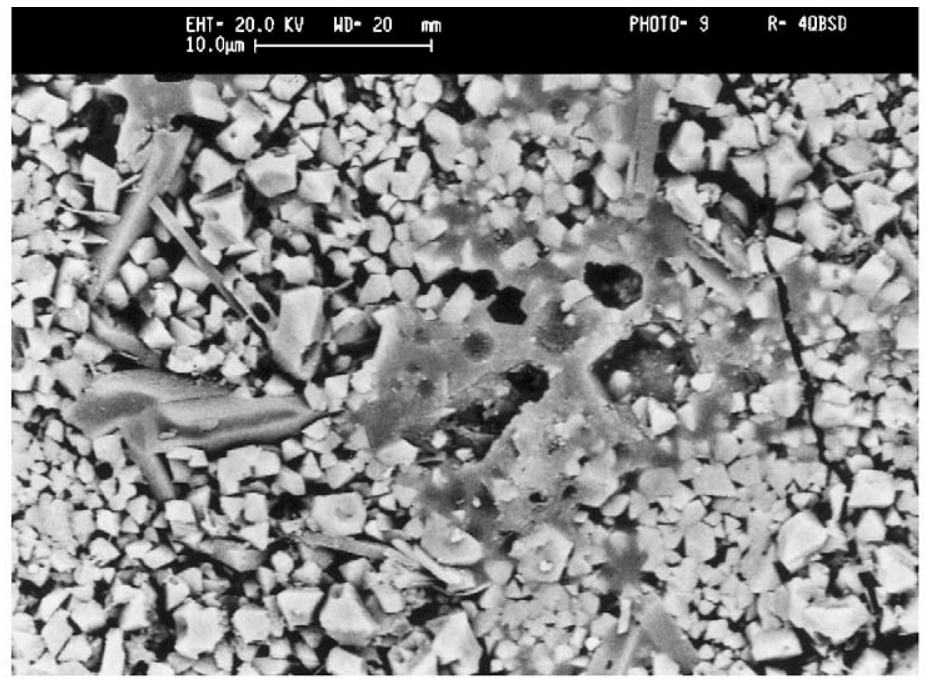

(A)

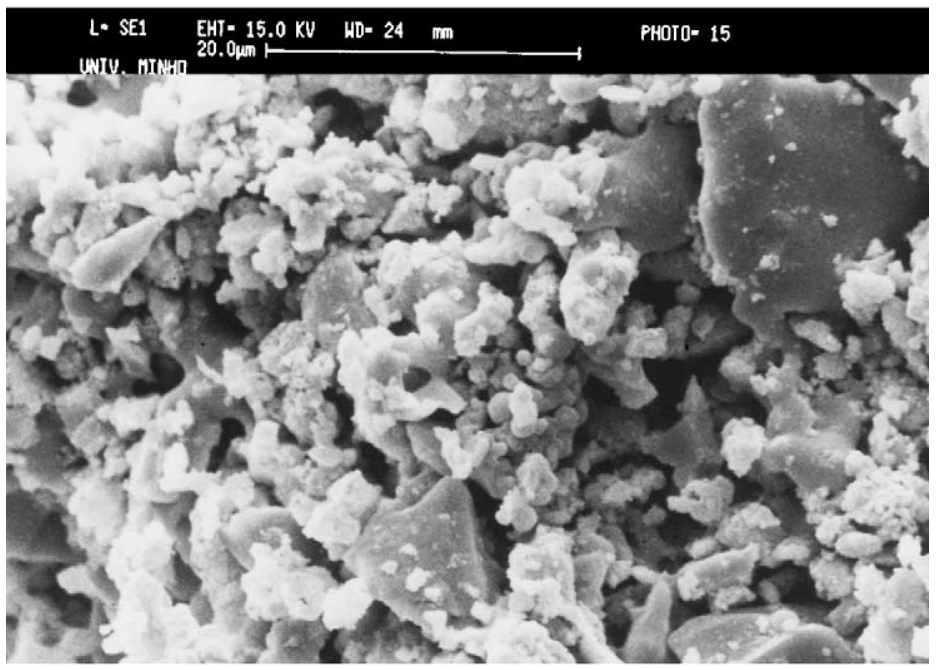

(B)

Fig. 6. Morphological aspect (SEM) of calcined samples: (A) pure $A$ sludge and (B) $A$ sludge/clay mixture.

trix contains coarser quartz grains that are less reactive. Despite the expected benefits of silicates formation involving sludge components on inactivation, the firing temperature is not enough high to assure an effective diffusional transport essential to promote those reactions in a large extent. In such conditions, the role of physical parameters seems to be prevalent over chemical ones. As detailed in another work [18] a macro-encapsulation mechanism is dominant in the actual experimental conditions. This hypothesis is supported by the incipient formation of new phases, undetectable by XRD (Fig. 7). In this figure, patterns of phases belonging to the $M$ sludge (e.g., spinels such as $\mathrm{Cr}_{1-x} \mathrm{Fe}_{x} \mathrm{O}_{3}, \mathrm{Ni}_{1-y} \mathrm{Zn}_{y} \mathrm{O}$, $\mathrm{Zn}_{1-z} \mathrm{Ni}_{z} \mathrm{FeCrO}_{4}$ ) and to the clay-based material (quartz, and feldspar) are the only observed, with no signs of reaction between the two different components. The same result was obtained for all the other sludges.

As previously mentioned, calcium ions are also the highest removed species from fired samples (Figs. 3-5). This is certainly related with the instability of $\mathrm{CaO}$ in room conditions and the quick formation of soluble $\mathrm{Ca}(\mathrm{OH})_{2}$. Moreover, the presence of the non-decomposable sulphate also contributes to this result, since it is somewhat soluble. By contrast, $\mathrm{Ni}$ is weakly removed even from sludges where its concentration is relevant $(J)$. Copper is the main constituent of sludge $Q$, and seems to be effectively immobilised both in aqueous and in acetate media. The formation of oxides of both species that remain stable even in moderately low $\mathrm{pH}$ values (down to about 4) is responsible for this behaviour.

The role of the time for the mixing preparation of suspensions on the effectiveness of the inertization process was evaluated with sludge $A$. The increase of the mixing time should promote: (i) a stronger de-aggregation of sludge floccules and decrease of average grain size, which improve the overall reactivity; (ii) the possible change of the nature of chemical species, namely hydroxides; and (iii) the adsorption of cationic species on the surface of clay particles 


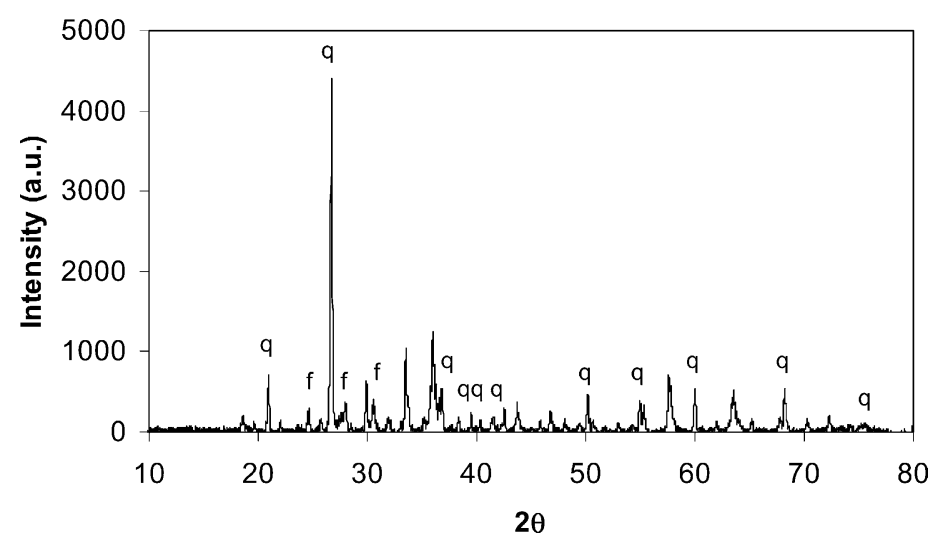

Fig. 7. XRD spectrum of $M$ sludge/clay mixture after calcination at $1000^{\circ} \mathrm{C}$. Patterns of phases belonging to the clay-based component (q: quartz; f: feldspar) are the only signed. Additional peaks belong to the calcined sludge.

which expectably increases the inertness of non-fired samples. The effect of item (i) on the inertness of the mixtures seems to be dependent on the effectiveness of the reactions that occur during firing. For dried or incipiently-fired samples, the dispersibility/availability of metallic species should decrease the inertness of samples. However, once promoted an effective reaction between sludge and clay components or by transforming sludge species into stable phases like oxides, the final inertness should increase. This requires a suitable firing schedule in order to active macro and/or micro-encapsulation mechanisms. These contradictory effects are well demonstrated for $A 1$ and $A 2$ samples. The last ones show a clear decrease of leaching levels only after firing at $1000^{\circ} \mathrm{C}$, while seem less inert than $A l$ ones before firing (Figs. 3-5). Differences are enhanced by the use of more aggressive extraction media (see Fig. 5).

\section{Conclusions}

Compositional and physical relevant properties of the sludge and stirring time during preparation of sludge/clay mixture suspensions seem to have a determinant role in the inertization of metallic species by incorporation in ceramic materials. The amount and type of metallic species obviously determine the leaching behaviour of each sludge or sludge/clay mixture. However, the nature of the non-metallic counterpart also determines the final stability of fired phases and, in consequence, also affects the inertness level. The ratio between metallic and non-metallic elements in the sludge is also related with its specific surface area, which is a determining physical parameter of the reactions extent upon firing. At $1000^{\circ} \mathrm{C}$, reactions between sludge and clay particles seem to be low extent (no new phases were detected) than those occurring between each isolated component (sludge and clay particles), pointing out the prevalence of a macro-encapsulation mechanism.

The increase of stirring effectiveness during preparation of mixture suspensions induces contradictory effects on the immobilisation degree of fired and non-fired samples. Before firing, the increasing dispersability/availability of smaller metallic particles in the microstructure tends to decrease the immobilisation level of samples. However, increasing reactivity of finer particles upon firing will promote an increasing effectiveness of the inertization level of calcined samples.

\section{References}

[1] EC norm 94/904.

[2] M. Albuquerque, J.M. Flores, J.A. Labrincha, Ind. Ceram. 22 (2002) 87.

[3] C. Palmonari, A. Tenaglia, Miner. Petrogr. Acta 29A (1985) 547.

[4] S. Stefanov, Ziegelindustrie Int. 3 (1986) 137.

[5] J.E. Alleman, Interbrick 3 (1987) 14.

[6] D.A. Pereira, D.M. Couto, J.A. Labrincha, CFI-Ceram. Forum Int. 77 (2000) 21.

[7] E.A. Dominguez, R. Ullmann, Appl. Clay Sci. 11 (1996) 237.

[8] R.E. Grim, in: Clay Mineralogy, second ed., McGraw-Hill, New York, 1968.

[9] D.M.S. Couto, C.M.S. Rodrigues, R.F. Silva, J.A. Labrincha, Am. Ceram. Soc. Bull. 12 (2003) 9101.

[10] D.U. Tulyaganov, S.M.H. Olhero, M.J. Ribeiro, J.M.F. Ferreira, J.A Labrincha, J. Mater. Synth. Process. 10 (2002) 311.

[11] F.R. Pereira, A.F. Nunes, A.M. Segadães, J.A. Labrincha, Refractory mortars made of different wastes and natural sub-products, Key Eng. Mater., in press.

[12] M.J. Ribeiro, D.U. Tulyaganov, J.M. Ferreira, J.A. Labrincha, Ceram. Int. 28 (2002) 319.

[13] P. Nunes, M.J. Ribeiro, J.M.F. Ferreira, C.S. Bóia, J.A. Labrincha, in: B. Bjorkman, C, Samuelsson, J. Wikstrom (Eds.), Proceedings of the TMS Fall Meeting on Recycling and Waste Treatment in Mineral and Metal Processing: Technical and Economic Aspects, Lulea, Sweden, 2002, vol. 2, pp. 359-368.

[14] E. Martelon, J. Jarrige, M.J. Ribeiro, J.M. Ferreira, J.A. Labrincha, Ind. Ceram. 20 (2000) 71.

[15] R. Conner, in: Environmental Engineering in the Process Plan, McGraw-Hill, New York, 1992, pp. 107-114.

[16] J.A. Slim, R. Wakefield, Water SA 17 (1991) 197.

[17] J. Magalhães, J.E. Silva, F.P. Castro, J.A. Labrincha, Effect of experimental variables on the inertization of galvanic sludges in clay-based ceramics, J. Hazard. Mater., in press.

[18] J. Magalhães, J.E. Silva, F.P. Castro, J.A. Labrincha, Kinetic study of the immobilization of galvanic sludge by incorporation in clay-based matrix, J. Environ. Eng.-ASCE, submitted for publication. 